\title{
P02-138
}

\section{FORENSIC PARENTING EVALUATIONS: CHALLENGES INHERENT IN THE EVALUATION OF LATIN AMERICAN PARENTS FOR THE USA COURTS}

\section{Guzman-Hosta ${ }^{1,2}$}

${ }^{1}$ Essex County Juvenile Court Clinic, Lynn, ${ }^{2}$ Children's Charter, Forensic Team, Waltham, USA

Most often a mental health professional is consulted by the court in cases involving the Care and Protection of children. Most often judges are interested in learning about the emotional and cognitive strengths and weaknesses of parents to aid in the decision making process. The court is most essentially interested in recommendations that could increase the likelihood of the successful reunification of a family. When reunification is not possible, the expert is often consulted regarding the prospect of successful supervised visits or whether an open adoption is a viable option. The complexity of the cases can exponentially increase when the parent who is being evaluated is a Latin American immigrant. Factors such as a history of trauma and oppression, language barriers, education and literacy issues impact the already complex nature of these cases. Another important factor is the differences in parenting across cultures. As multicultural evaluators for the court we are in a unique position to offer education regarding sociocultural issues, and the impact of the dominant culture on an immigrant family. This presentation aims to illustrate and discuss the challenges inherent in these evaluations and to propose recommendations for improvement of the field. 